DOI: 10.4274/jarem.galenos.2021.25733

J Acad Res Med 2021;11(1):90-96

\title{
Retrospective Evaluation of the Neonatal Cholestasis Cases
}

\author{
(D) Elif Sağ1, (1) Emine Esra Öztürk2, (1) Hatice Sonay Yalçın Cömert33, (1) Yakup Arslan4, (1) Süleyman Caner Karahan5, \\ (1) Murat Çakır ${ }^{1}$ \\ ${ }^{1}$ Karadeniz Technical University Faculty of Medicine, Department of Children's Health and Diseases, Division of Pediatric Gastroenterology, \\ Hepatology and Nutrition, Trabzon, Turkey \\ ${ }^{2}$ Karadeniz Technical University Faculty of Medicine, Department of Children's Health and Diseases, Trabzon, Turkey \\ ${ }^{3}$ Karadeniz Technical University Faculty of Medicine, Department of Pediatric Surgery, Trabzon, Turkey \\ ${ }^{4}$ Karadeniz Technical University Faculty of Medicine, Department of Children's Health and Diseases, Divison of Neonatology, Trabzon, Turkey \\ ${ }^{5}$ Karadeniz Technical University Faculty of Medicine, Department of Medical Biochemistry, Trabzon, Turkey
}

Cite this article as: Sağ E, Öztürk EE, Yalçın Cömert HS, Arslan Y, Karahan SC, Çakır M. Retrospective Evaluation of the Neonatal Cholestasis Cases. J Acad Res Med 2021;11(1):90-96

\begin{abstract}
Objective: Neonatal cholestasis is a condition that begins in the first months of life and is accompanied by a direct increase in bilirubin and jaundice as a result of deterioration in bile production or excavation. Early and accurate diagnosis is important for treatment success and prognosis. In this study, we aimed to examine the demographic characteristics, etiological factors, clinical signs, treatment and final conditions of patients monitored for neonatal cholestasis and to determine the etiological factors of liver transplant patients.

Methods: Patients who were diagnosed with cholestasis in the neonatal period ( $<6$ months) and followed up in our clinic for at least six months between January 2005 and January 2018 were included in the study. The clinical course and final status of the patients were recorded retrospectively. Results: The median age of onset of jaundice in 131 patients (61.1\% male) enrolled in the study was 6 days (range: 1-180 days). Ninety-nine (75.6\%) patients were in the intrahepatic cholestasis group, and 32 (24.4\%) were in the extrahepatic cholestasis group. In the intrahepatic cholestasis group, total parenteral nutrition-related cholestasis (27.3\%) was the most common, and biliary atresia (71.9\%) was the most common in the extrahepatic cholestasis group. Other main reasons were systemic (19.1\%), metabolic (12.2\%), hereditary cholestatic diseases (9.9\%) and infectious (7.6\%) causes. The median time of Kasai portoenterostomy in patients with biliary atresia was 64 days (range: $28-180$ days). The highest (44\%) mortality rate was in the patients with systemic disease-related cholestasis. Liver transplantation $(n=21,16 \%)$ was the most frequently performed in patients with biliary atresia. Conclusion: Early diagnosis and timely treatment are very important for the optimal prognosis in neonatal cholestasis. The presence of acholic stools, maturity, early onset of jaundice and high gamma-glutamyl transferase levels should suggest biliary atresia. Early surgical treatment is warranted once the diagnoses was made, and liver transplantation is a treatment method that increases survival rate in these patient groups.
\end{abstract}

Keywords: Biliary atresia, transplant, neonatal cholestasis

ORCID IDs of the authors: E.S. 0000-0003-3069-2872; E.E.Ö. 0000-0001-7628-0641; H.S.Y.C. 0000-0002-5281-4933; Y.A. 0000-0002-9079-1701; S.C.K. 0000-0001-5091-081X; M.Ç. 0000-0001-8789-8199. 


\section{INTRODUCTION}

Neonatal cholestasis is a condition that starts in the first months of life and progresses with direct (conjugated) bilirubin increase and jaundice as a result of impaired bile production or excretion (1). Its incidence is known as 1 in 2,500 live births (2). As a result of increased conjugated bilirubin and bile acids, toxin components cause liver damage and cause hepatobiliary dysfunction. Therefore, in a patient presenting with jaundice, it is critical to distinguish whether the jaundice is cholestatic or not.

Newborn babies, especially premature ones, are prone to cholestasis. The reasons of this are because of the irregularity in canalicular structure and function, the increase in hypomotility and paracellular permeability, and the decrease in hepatic immaturity and bile flow. Hepatic maturation is complete around the end of the first year. Therefore, there is no consensus regarding the age range of neonatal cholestasis. In most studies, it was considered to be about the first six months (3).

The most common cause of neonatal cholestasis is intrahepatic cholestasis (60-70\%), and most of these cases are idiopathic neonatal hepatitis (INH) (4). INH covers a group of patients whose etiology cannot be found or whose specific diagnosis cannot be made by existing examinations rather than a diagnosis. Although it has been determined in studies that more than half of the cholestatic infants are patients with $I N H$, the rate of $I N H$ diagnosis has decreased in recent years thanks to clinical and molecular developments (5). Infections [toxoplasmosis, rubella, cytomegalovirus (CMV), herpes virus, TORCH and syphilis], endocrinopathies (hypothyroidism, hypopituitarism, adrenal insufficiency), systemic diseases, genetic-chromosomal disorders, metabolism diseases, total parenteral nutrition (TPN), hereditary cholestatic diseases and anatomical disorders are other causes of intrahepatic cholestasis (6). Most patients with extrahepatic cholestasis are diagnosed with biliary atresia (BA). In etiological studies reported from different centers, BA accounted for about $25-35 \%$ of all neonatal cholestasis cases, while other major causes were genetic disorders (25\%), metabolic diseases (20\%) and alpha-1 antitrypsin deficiency (10\%) (7). In recent years, the frequency of TPN-related neonatal cholestasis cases has also increased as a result of increased life rates of premature and low birth-weighted newborns.

Early and accurate diagnosis of neonatal cholestasis patients is very important for treatment success and prognosis. Evaluation of these patients is difficult due to the variety of cholestatic syndromes and the lack of clinical manifestations specific to diseases. But thanks to clinical and molecular advances, differential diagnosis can be made more easily in recent years.

In this study, it was planned to examine the neonatal cholestasis cases followed in our clinic with their demographic characteristics, etiological factors, clinical signs, treatment and final status and to compare these data with other studies in the literature.

\section{METHODS}

Patients diagnosed with neonatal cholestasis (0-6 months old) and followed for at least six months in the Karadeniz Technical University Faculty of Medicine Pediatric Gastroenterology, Hepatology and Nutrition Department between January 2005 and January 2018 were included in this study. Cholestasis was considered to be conjugated bilirubin levels above $1 \mathrm{mg} / \mathrm{dL}$ when serum total bilirubin levels were below $5 \mathrm{mg} / \mathrm{dL}$, or conjugated bilirubin was more than $20 \%$ of total when total bilirubin levels were above $5 \mathrm{mg} / \mathrm{dL}(5,8)$. Demographic characteristics, etiological factors, clinical signs, treatment and final status of patients were examined and etiological factors were determined in the liver transplant cases.

Causes of cholestasis were grouped as extrahepatic and intrahepatic cholestasis. Intrahepatic cholestasis; i) INH, ii) metabolic diseases, iii) hereditary cholestatic syndromes, iv) infectious diseases, v) systemic diseases, vi) toxins (TPN, drugs), vii) anatomical disorders of the biliary tract, viii) undiagnosed extrahepatic cholestasis was classified as i) BA, ii) choledochal cysts, iii) biliary hypoplasia, iv) cholelithiasis (9).

Ethics committee approval was obtained from the Karadeniz Teknik University Faculty of Medicine Scientific Research Ethics Committee for the study (approval number: 2016/128, approval date: 21.09.2016). Our study was conducted in accordance with the ethical principles of the Declaration of Helsinki. Consent was obtained from the patients.

\section{Statistical Analysis}

Statistical analysis was performed using "SPSS ${ }^{\circledR}$ for Windows version 22.0" (IBM Corp., Released 2013, IBM SPSS Statistics for Windows, Version 22.0. Armonk, NY, USA). Descriptive statistics of evaluation results; number and percentage for categorical variables, mean \pm standard deviation for continuous variables were given as minimum, maximum, and median. Chi-square test was used to analyze the differences between the ratios of categorical variables in independent groups. Statistical significance level of alpha was accepted as $p<0.05$.

\section{RESULTS}

A total of 131 patients were enrolled in the study [61.1\% male, median age; 35 days (range: 1-180 days)]. Patients' median age of onset of jaundice; it was 6 days (range: 1-180 days). Forty-three patients (32.8\%) had prematurity and parents of 43 patients (32.8\%) had a consanguineous marriage. The findings other than jaundice were hepatomegaly ( $n=102,77.9 \%)$, splenomegaly ( $n=48,36.6 \%)$, acholic stool ( $n=46,35.1 \%)$, umbilical hernia $(n=9,6.9 \%)$, limb anomaly $(n=7,5.3 \%)$ and atypical facial appearance $(n=7,5.3 \%)$. The demographic and clinical features of the patients at the time of application are shown on Table 1.

Patients were divided into two groups according to their diagnosis. Extrahepatic cholestasis was detected in 32 (24.4\%) patients and intrahepatic cholestasis was detected in 99 (75.6\%) patients. Recent diagnoses of patients are shown in Table 2. 


\begin{tabular}{|c|c|}
\hline $\begin{array}{l}\text { Demographic characteristics at the time of } \\
\text { admission }\end{array}$ & $\begin{array}{l}\text { Number of patients } \\
(n=131) n(\%)\end{array}$ \\
\hline \multicolumn{2}{|l|}{ Age of admission, days } \\
\hline Mean \pm SD & $45.2 \pm 41.3$ \\
\hline Median & 35 \\
\hline $30 \leq$ days, $n(\%)$ & $52(39.7)$ \\
\hline $31-90$ days, $n(\%)$ & $63(48.1)$ \\
\hline $91-150$ days, $n(\%)$ & $9(6.9)$ \\
\hline $151-180$ days, $n(\%)$ & $7(5.3)$ \\
\hline \multicolumn{2}{|l|}{ Gender, n (\%) } \\
\hline Female & $51(38.9)$ \\
\hline Male & $80(61.1)$ \\
\hline \multicolumn{2}{|l|}{ Age of onset of jaundice, day } \\
\hline Mean \pm SD & $22.7 \pm 35.0$ \\
\hline Median & 6 \\
\hline $15<$ days, $n(\%)$ & $81(61.8)$ \\
\hline $15 \geq$ days, $n(\%)$ & $50(38.2)$ \\
\hline Prematurity, n (\%) & $43(32.8)$ \\
\hline 34-37 weeks & $23(53.5)$ \\
\hline 30-33 weeks & $12(27.9)$ \\
\hline $30<$ week & $8(18.6)$ \\
\hline Close kinship, n (\%) & $43(32.8)$ \\
\hline
\end{tabular}

\section{Table 2. Distribution of patients by diagnosis}

\begin{tabular}{|c|c|c|c|c|}
\hline Localization & Etiology & $\begin{array}{l}\text { Number of } \\
\text { patients; } n\end{array}$ & (\%) & Total \\
\hline \multirow{4}{*}{$\begin{array}{l}\text { Extrahepatic } \\
\text { cholestasis }\end{array}$} & Biliary atresia & 23 & 17.6 & \multirow{4}{*}{$24.4 \%$} \\
\hline & Choledoc cyst & 5 & 3.8 & \\
\hline & Cholelithiasis & 2 & 1,5 & \\
\hline & Biliary hypoplasia & 2 & 1.5 & \\
\hline \multirow{8}{*}{$\begin{array}{l}\text { Intrahepatic } \\
\text { cholestasis }\end{array}$} & $\begin{array}{l}\text { TPN-associated } \\
\text { cholestase }\end{array}$ & 27 & 20.7 & \multirow{8}{*}{$75.6 \%$} \\
\hline & $\begin{array}{l}\text { Associated with } \\
\text { systemic disease }\end{array}$ & 25 & 19.1 & \\
\hline & Metabolic causes & 16 & 12.2 & \\
\hline & $\begin{array}{l}\text { Hereditary } \\
\text { cholestatic } \\
\text { diseases }\end{array}$ & 13 & 9.9 & \\
\hline & $\begin{array}{l}\text { Associated with } \\
\text { infection }\end{array}$ & 10 & 7.6 & \\
\hline & Undiagnosed & 4 & 3.1 & \\
\hline & $\begin{array}{l}\text { Idiopathic } \\
\text { neonatal hepatitis }\end{array}$ & 2 & 1.5 & \\
\hline & $\begin{array}{l}\text { Anatomical } \\
\text { disorder }\end{array}$ & 2 & 1.5 & \\
\hline
\end{tabular}

BA ( $n=23$ ) constituted $71.9 \%$ of patients with extrahepatic cholestasis and $17.6 \%$ of all patients with cholestasis. Kasai portoentrostomy was performed in 22 (95.7\%) of the patients with BA after the diagnosis was made by intraoperative cholangiography. The mean age of Kasai portoentrostomy was 68.6 \pm 33.5 (median: 64 days, range: 28-180) days. Since one patient $(4.3 \%)$ presented late $\left(225^{\text {th }}\right.$ day), liver transplantation was performed in the follow-up before Kasai operation could be performed. Liver transplantation was performed in 10 (43.5\%) of 22 patients who underwent Kasai operation (all living donors). All of the transplant patients $(n=11,47.8 \%)$ are alive and their median age at present is 6.8 years (range: 0.9-13.5 years). Three (25\%) of the 12 patients who did not have a transplant, died due to decompensated cirrhosis while waiting on the transplant list. When liver function was evaluated in nine living patients (39.1\%), seven patients (30.4\%) had compensated cirrhosis, and two patients $(8.7 \%)$ had decompensated cirrhosis. Among all BA patients, there were three (13\%) patients with excitus, and $20(87 \%)$ patients who survived. Other causes of extrahepatic cholestasis $(n=9)$ were biliary cyst $(n=5)$, biliary hypoplasia $(n=2)$, and cholelithiasis $(n=2)$. Cystectomy was performed in five patients with biliary cyst, external drainage was performed on a patient with biliary hypoplasia, cholecystectomy was performed on a patient with cholelithiasis, and other patients were followed up with medical treatment.

Most patients in the intrahepatic cholestasis group had TPNassociated cholestasis ( $n=27,27.3 \%)$. The cases of $21(77.8 \%)$ and premature indications for TPN; necrotizing enterocolitis (NEC) $(n=13,48.1 \%)$, short bowel syndrome $(n=7,36 \%)$, sepsis $(n=5$, $18.5 \%)$, Pierre-Robin variant $(n=1,3.7 \%)$ and anatomical problems $(n=1,3.7 \%)$. Patients were given cyclic fat support $(n=27$, lipid $1 \mathrm{~g} /$ $\mathrm{kg} /$ day three days a week), ursodeoxycholic acid ( $\mathrm{n}=22,15 \mathrm{mg} /$ $\mathrm{kg} /$ day), $\mathrm{N}$-acetylcysteine ( $\mathrm{n}=4,5 \mathrm{mg} / \mathrm{kg} /$ hour-5 days), omega-3 $(n=1,1-2 \mathrm{~mL} / \mathrm{kg}$ ) therapy as a treatment protocol. In follow-up, five patients had died due to sepsis (two with fungal sepsis, three with catheter-related sepsis). The average follow-up period of living patients ( $n=22,77.8 \%$ ) was 5.6 years (range: $1-11.5$ years) and liver function tests were normal in their last applications.

In the metabolic diseases group ( $n=16,16.2 \%)$; four patients (25\%) galactosemia (homozygous Q188R mutation), four patients (25\%) tyrosinemia, two patients (12.5\%) cystic fibrosis (CFTR gene; p.F508del homozygous mutation), one patient (6.3\%) was diagnosed with Wollman's disease. Five patients (31.3\%) were described as possible metabolic diseases due to non-specific changes in their metabolic tests, a history of close kinship, a history of infant death, coagulopathy, and ascites. A lactosefree diet for patients with galactosemia, a diet for patients with tyrosinemia and NTBC (1 mg/kg), and medical treatment for patients with cystic fibrosis (pancreatic enzyme replacement, medium-chain triglyceride fat support and vitamin $A, D, E, K)$ were initiated. In follow-up, 10 patients underwent medical treatment as well as a new diet, and three patients $(n=4,25 \%)$ who had Wollman's disease and were considered a possible metabolic 
35 days (range: 1-68 days). One of the patients died five days after being diagnosed with Caroli syndrome. While the other patient was being followed up with the diagnosis of congenital hepatic fibrosis and autosomal recessive (AR) polycystic kidney disease, liver transplantation (live donor) was performed due to decompensated cirrhosis, and the patient died due to sepsis after transplantation.

INH group ( $n=2,2 \%$ ) comprised $1.5 \%$ of all patients with cholestasis. Patients with unfitting clinical and laboratory findings to a specific disease group and with undetermined cholestasis etiology were evaluated as INH. All patients had hepatomegaly and splenomegaly on physical examination. One (50\%) of $\mathrm{INH}$ patients received liver transplantation at the age of seven months (living donor). The liver functions of the other patient are normal and follow-up continues.

Four patients (4\%) who could not be diagnosed constituted 3.1\% of all patients with cholestasis. One of these patients (25\%) died at the age of two months and the etiology was not found. The median follow-up period of the surviving patients was 5.8 years (range: 0.9-10.7 years). Liver functions of three patients who were living in the follow-up were completely normalized.

When BA and other diseases are compared; while there was no significant difference in terms of gender and kinship, a significant difference was found in the age of onset of acholic defecation, jaundice, gestational week and gamma-glutamyl transferase (GGT) ( $p<0.001, p=0.028, p=0.001$ and $p=0.001$, respectively) (Table 3).

When the last conditions of the patients are evaluated; liver transplantation was performed in $21(16 \%)$ of 131 patients (20 living, one cadaver donor) (Table 4). 99 (75.6\%) of all patients were alive $(61.1 \%$ with their own liver, $14.5 \%$ after transplantation) 32 of them (24.4\%) were exitus (22.9\% with their own liver and $1.5 \%$ after transplantation). Both five-year and 10-year survival rates of BA patients were $86 \%$. Five-year and 10 -year survival rates of systemic disease-related cholestasis cases with the highest mortality were determined as $56 \%$. The final status of the patients is shown in Table 5.

\begin{tabular}{|l|l|l|l|}
\hline \multicolumn{3}{|c|}{ Table 3. Comparison of biliary atresia and other diseases } \\
\hline & $\begin{array}{l}\text { Biliary } \\
\text { atresia } \\
(\mathbf{n}=\mathbf{2 3})\end{array}$ & $\begin{array}{l}\text { Other } \\
\text { cholestatic } \\
\text { diseases } \\
(\mathbf{n}=108)\end{array}$ & $\mathbf{p}$ \\
\hline Gender, n (\%), M & $11(47.8)$ & $69(63.9)$ & 0.231 \\
\hline $\begin{array}{l}\text { Age of onset of jaundice, } \\
\text { day, mean } \pm \text { SD }\end{array}$ & $3.4 \pm 22.8$ & $24.7 \pm 36.9$ & 0.028 \\
\hline Prematurity, n (\%) & 0 & $43(39.8)$ & 0.001 \\
\hline Week of birth, mean \pm SD & $38.9 \pm 0.7$ & $36.3 \pm 3.8$ & 0.001 \\
\hline Acolic defecation, $n(\%)$ & $21(91.3)$ & $25(23.1)$ & $<0.001$ \\
\hline Close kinship, $n$ (\%) & $6(26.1)$ & $37(34.3)$ & 0.608 \\
\hline GGT values (U/L) & $477.9 \pm 336.4$ & $274.7 \pm 317.2$ & 0.001 \\
\hline GGT: gamma-glutamyl transferase, SD: standard deviation & \\
\hline
\end{tabular}




\begin{tabular}{|c|c|c|c|c|c|c|}
\hline & Number & $\begin{array}{l}\text { Transplant age } \\
\text { (median) }\end{array}$ & Gender & Donor & $\begin{array}{l}\text { Final } \\
\text { situation }\end{array}$ & $\begin{array}{l}\text { Current age } \\
\text { (median) }\end{array}$ \\
\hline Biliary atresia & 11 & $\begin{array}{l}13 \text { months } \\
\text { (5-152 month) }\end{array}$ & $\begin{array}{l}\text { Female }(n=7) \\
\text { Male }(n=4)\end{array}$ & Living donor & Live & $\begin{array}{l}6.8 \text { years } \\
(0.9-13.5 \text { years })\end{array}$ \\
\hline PFIC & 4 & $\begin{array}{l}29.5 \text { ay } \\
\text { (5-66 month) }\end{array}$ & $\begin{array}{l}\text { Female }(n=2) \\
\text { Male }(n=2)\end{array}$ & Living donor & Live & $\begin{array}{l}8.8 \text { years } \\
\text { (3.7- } 13.5 \text { years) }\end{array}$ \\
\hline Alagille syndrome & 1 & 2 month & Female & Living donor & $\begin{array}{l}\text { Exitus after } 8 \\
\text { months }\end{array}$ & - \\
\hline $\mathrm{INH}$ & 1 & 7 month & Female & Living donor & Live & 5 years 7 months \\
\hline $\mathrm{OIHA}+\mathrm{OlH}$ & 1 & 4 month & Male & Living donor & Live & 7 years \\
\hline Tyrosinemia & 1 & 32 month & Male & Cadaver donor & Live & 8 years 1 month \\
\hline Tirozinemi-HCC & 1 & 14 month & Female & Living donor & Live & 9 years 5 months \\
\hline ORPCKD+CHF & 1 & 6 month & Female & Living donor & $\begin{array}{l}\text { Exitus after } 2 \\
\text { months }\end{array}$ & - \\
\hline
\end{tabular}

HCC: hepatocellular carcinoma, INH: idiopathic neonatal hepatitis, OIHA+OIH: giant cell autoimmune hepatitis and autoimmune hemolytic anemia, ORPCKD+CHF: autosomal recessive polycystic kidney disease + congenital hepatic fibrosis, PFIC: progressive familial intrahepatic cholestasis

\begin{tabular}{|c|c|c|c|c|c|c|c|}
\hline Feature & $\mathrm{n}$ & $\begin{array}{l}\text { Living with his own } \\
\text { liver } \\
\mathrm{n}(\%)\end{array}$ & $\begin{array}{l}\text { After living } \\
\text { liver } t x \\
\mathrm{n}(\%)\end{array}$ & $\begin{array}{l}\text { Total living } \\
\mathrm{n}(\%)\end{array}$ & $\begin{array}{l}\text { Exitus with his } \\
\text { own liver } \\
\mathrm{n}(\%)\end{array}$ & $\begin{array}{l}\text { Exitıs after } \\
\text { living liver } t x \\
n(\%)\end{array}$ & $\begin{array}{l}\text { Total exitus } \\
\mathrm{n}(\%)\end{array}$ \\
\hline Biliary atresia & 23 & $9(39.2)$ & $11(47.8)$ & $20(87)$ & $3(13)$ & - & $3(13)$ \\
\hline Other extrahepatic causes & 9 & 8 (88.9) & - & 8 (88.9) & $1(11.1)$ & - & $1(11.1)$ \\
\hline Systemic diseases & 25 & $13(52)$ & $1(4)$ & $14(56)$ & $11(44)$ & - & $11(44)$ \\
\hline Metabolic causes & 16 & $10(62.5)$ & $2(12.5)$ & $12(75)$ & $4(25)$ & - & $4(25)$ \\
\hline $\begin{array}{l}\text { Hereditary cholestatic } \\
\text { diseases }\end{array}$ & 13 & $6(46.2)$ & $4(30.8)$ & $10(77)$ & $2(15.4)$ & $1(7.6)$ & $3(23)$ \\
\hline Associated infection & 10 & $8(80)$ & - & $8(80)$ & $2(20)$ & - & $2(20)$ \\
\hline
\end{tabular}

\section{DISCUSSION}

Evaluation of patients with cholestasis is difficult due to the variety of cholestatic syndromes and nonspecific clinical findings. With a clearer understanding of the mechanisms of the hepatobiliary system, differential diagnosis can be made better recently. Considering the etiology of 131 patients in our study; (i) intrahepatic cholestasis was detected in the majority of cases (75.6\%) and most of this was TPN-related cholestasis (27.3\%), (ii) the majority of cases with extrahepatic cholestasis had BA (71.9\%), (iii) Kasai portoenterostomy in BA patients, it was observed that the median time was 64 days, (iv) the majority of the cases undergoing liver transplantation were BA (52.4\%), (v) the mortality of cholestasis cases associated with systemic disease was high (44\%).

In our study, the etiology of neonatal cholestasis was determined to be $60-70 \%$ intrahepatic cholestasis, similar to other studies in the literature. The majority of intrahepatic cholestasis cases are INH and TPN-related cholestasis, depending on the period during which the study was conducted (4). In recent years, the rate of INH diagnosis has decreased as a result of clinical and molecular developments (5). As in our study, the frequency of TPN cholestasis is increasing due to better neonatal care of premature and low birth weight babies and better treatment of complications. Most of the risk factors in the studies are NEC, sepsis and major intestinal surgeries (10). The best treatment method is to start enteral nutrition as soon as possible and stop parenteral nutrition, and omega-3 supplementation and lipid reduction are other recommended applications (11). Although organ transplantation is required for long-term TPN cholestasis due to liver failure and cirrhosis, in our cases, there was no need for liver transplantation. The cause of death of the vast majority of patients who have died is sepsis associated with catheter or blood flow.

The most common and most important cause of extrahepatic cholestasis is BA (12). Although the centers vary depending on the 
patient density, BA accounts for 20-35\% of all cholestasis. A study conducted in our country found that $16.8 \%$ of all cholestasis cases constitute extrahepatic cholestasis, while $75 \%$ of extrahepatic cholestasis is BA (13). In another study, the BA rate was found to be $25.9 \%(438 / 1,692)$ in all neonatal cholestasis patients $(5)$. Early diagnosis and treatment in $\mathrm{BA}$ is very important for prognosis. In cases where early diagnosis was made and Kasai portoenterostomy was performed at an early age, it was observed that the need for liver transplantation was less (12). The median time for Kasai portoenterostomy in our center was 64 days. Compared to other studies, our center found that the age of operation Kasai is similar to that of many centers. It was reported as 63 days in an organ transplant center in America and 66 days in another study based in London $(14,15)$.

Although acholic stools are specific for BA, the bile ducts must be visualized by intraoperative cholangiography for definitive diagnosis. Until now, various objective scoring systems have been created for BA to reduce the need for unnecessary intraoperative cholangiography, and a diagnosis has been attempted noninvasively. In a study conducted in America; acholic stools, high GGT (>204 U/L) and normal weight Z score were found to be associated with BA (12). In a study conducted in our country; it has been reported that ultrasonography findings, high GGT (>197 $\mathrm{U} / \mathrm{L}$ ) and acholic stools are associated with BA (16). Our study also found that acholic stool and GGT height were significant for BA, similar to these studies in the literature.

The liver is one of the most important target organs of metabolic diseases. In the neonatal period, patients with galactosemia, tyrosinemia and cystic fibrosis can apply with signs of acute liver failure. In a study, $36.5 \%$ (27/74) of 74 patients with metabolic disease and cholestasis were diagnosed with galactosemia, $8.1 \%$ (6/74) of them were diagnosed with tyrosinemia. In the same study, the diagnosis of cystic fibrosis was found at a rate of $0.89 \%$ $(15 / 1,692)$ in the general screening (4). In our study, the rate of metabolic disease was determined as $12.1 \%$ and galactosemia and tyrosinemia were most commonly detected. In most AR inherited diseases, detailed questioning of family history and close kinship is important, and early diagnosis and treatment are important.

Especially in recent years, an increase in the diagnosis of hereditary cholestatic syndromes has been observed with the increase in molecular studies. In addition to jaundice, signs such as itching, diarrhea, growth retardation in patients are significant in terms of PFIC; skeletal abnormalities, typical facial appearance, pulmonary stenosis, and eye signs are significant in terms of Alagille syndrome (17). In these patients, both due to liver failure and due to complications (itching, growth retardation, especially in patients diagnosed with PFIC, etc.) indication of liver transplantation may occur. Similar to the studies in the literature, in our study, liver transplantation was performed most often to these patients after BA.

When the literature is examined, cholestasis due to infectious diseases was observed with a rate of $2.6 \%(5 / 190)$ in a study conducted in our country, while it was seen at a rate of $7.7 \%$ in our study (13). In the large-scale screening conducted in the United States, cholestasis due to infection was observed at a rate of $11.5 \%$ (194/1692), and in the infectious group, 33.5\% of the patients were CMV infection, $3.6 \%$ toxoplasma infection, $24.7 \%$ sepsis and $9.8 \%$ urinary tract infections (UTI) (4). Cholestasis may also accompany bacterial sepsis. Mediators caused by bacterial products and endotoxins cause cholestasis, leading to changes in hepatic circulation and a decrease in bile flow. In a study conducted by Tiker et al. (18), the most common cause of cholestasis is sepsis (E.coli-UTI-related) and cholestasis findings developed on the $10^{\text {th }}$ day on average.

Even if neonatal cholestasis is a sign of liver disease, other systemic diseases involving the liver may also present with cholestasis. Therefore, when a cholestatic patient admits, it is recommended to investigate cardiac, renal and, if there are neurological findings, in terms of central nervous system malformations that may accompany. Similar to our study, in the study of Sarı et al. (13); echocardiography (echo) results mostly found atrial septal defect, patent foramen ovale, and peripheral pulmonary stenosis. These echo findings may sometimes accompany the disease incidentally and sometimes give clues about the etiology. In particular, peripheral pulmonary stenosis is significant in patients with Alagille syndrome. If we examine the renal findings, polycystic kidney findings are important for Caroli's disease, and and renal parenchymal echo findings are important for metabolic diseases.

Neonatal cholestasis accounts for more than half of the causes of liver transplantation in children, and the most common cause is known as BA (40\%-50\%). McDiarmid et al. (19) found that $33.5 \%$ of 1,187 liver transplant patients were under 1 year of age and $65.6 \%$ of these patients were BA. In another study conducted by Haberal et al. (20) in children, 101 liver transplants were performed and the most common indication was BA $(n=24,23.7 \%)$. In another liver transplant center, Zeytunlu et al. (21) examined 1,001 liver transplant patients (183 pediatric patients) and found the most common transplant indication in pediatric patients as cholestatic diseases (69\%) and the most common BA and PFIC in cholestatic diseases. Similarly in our study, the most common indications for transplantation are BA and hereditary cholestatic diseases.

\section{Study Limitations}

Our study is retrospective and based on patient file records. In addition, there are patients with idiopathic cholestasis who have not been diagnosed as a result of technical impossibilities (lack of metabolic and genetic examination methods) in the first years of the study.

\section{CONCLUSION}

The causes of cholestasis vary in the neonatal period. Early diagnosis and timely treatment are crucial for mortality, morbidity and optimal prognosis. Presence of acholic stools, maturity, early onset of jaundice and high GGT levels should primarily suggest BA. In particular, the diagnosis of BA and metabolic diseases that 
require early surgery is important, and liver transplantation is a treatment method that increases the survival rate in these groups of patients.

Ethics Committee Approval: Ethics committee approval was obtained from the Karadeniz Teknik University Faculty of Medicine Scientific Research Ethics Committee for the study (approval number: 2016/128, approval date: 21.09.2016).

Informed Consent: Consent form was obtained from the patients.

Peer-review: Externally peer-reviewed.

Author Contributions: Surgical and Medical Practices - E.S., E.E.Ö., H.S.Y.C., M.Ç.; Concept - E.S., M.Ç.; Design - E.S., M.Ç.; Data Collection and/or Processing - E.S., E.E.Ö., H.S.Y.C., Y.A., S.C.K., M.Ç.; Analysis and/ or Interpretation - E.S.; Literature Search - E.S., M.Ç.; Writing - E.S., M.Ç.

Conflict of Interest: The authors have no conflict of interest to declare.

Financial Disclosure: The authors declared that this study has received no financial support.

\section{REFERENCES}

1. Weiss AK, Vora PV. Conjugated hyperbilirubinemia in the neonate and young infant. Pediatr Emerg Care 2018; 34: 280-3.

2. Dick MC, Mowat AP. Hepatitis syndrome in infancy - an epidemiological survey with 10 year follow up. Arch Dis Child 1985; 60: 512-6.

3. Balistreri WF. Neonalal cholestasis. J Pediatr 1985; 106: 171-84.

4. Gottesman LE, Del Vecchio MT, Aronoff SC. Etiologies of conjugated hyperbilirubinemia in infancy: a systematic review of 1692 subjects. BMC Pediatr 2015; 15: 192.

5. Dani C, Pratesi S, Raimondi F, Romagnoli C. Italian guidelines for the management and treatment of neonatal cholestasis. Ital J Pediatr 2015; 41: 69.

6. Fawaz $R$, Baumann U, Ekong U, Fischler B, Hadzic N, Mack $C L$, et al. Guideline for the evaluation of cholestatic jaundice in infants: joint recommendations of the North American Society for pediatric gastroenterology, hepatology, and nutrition and the European Society for pediatric gastroenterology, hepatology, and nutrition. J Pediatr Gastroenterol Nutr 2017; 64: 154-68.

7. Balistreri WF, Bezerra JA. Whatever happened to "neonatal hepatitis"? Clin Liver Dis 2006; 10: 27-53.
8. Stormon MO, Dorney SF, Kamath KR, O'Loughlin EV, Gaskin KJ. The changing pattern of diagnosis of infantile cholestasis. J Paediatr Child Health 2001; 37: 47-50.

9. Wyllie R, Hyams JS. Pediatric gastrointestinal and liver disease, pathophysiology / diaognosis / management. In: Kay M, (ed). Saunders Elsevier, Chapter 58, 2006. p.851-68.

10. Sharef SW, Al-Sinani S, Al-Naamani K, Al-Zakwani I, Reyes ZS, Al-Ryhiami $\mathrm{H}$, et al. Incidence and risk factors of parenteral nutrition - associated cholestasis in omani neonates: single centre experience. Sultan Qaboos Univ Med J 2015; 15: 234-40.

11. Belza C, Thompson R, Somers GR, de Silva D, Fitzgerald K, Steinberg K, et al. Persistence of hepatic fibrosis in pediatric intestinal failure patients treated with intravenous fish oil lipid emulsion. J Pediatr Surg 2017; 52: 795-801.

12. Shneider BL, Moore J, Kerkar N, Magee JC, Ye W, Karpen SJ, et al. Childhood liver disease research network. Initial assessment of the infant with neonatal cholestasis - Is this biliary atresia? PLoS One 2017; 12: e0176275. doi: 10.1371/journal.pone.0176275.

13. Sarı S, Egritas Ö, Baris Z. Infantile cholestatic liver diseases: retrospective analysis of 190 cases. Turk Arch Ped 2012; 47: 167-71.

14. Hopkins PC, Yazigi N, Nylund CM. Incidence of biliary atresia and timing of hepatoportoenterostomy in the United States. J Pediatr 2017; 187: 253-7.

15. Hussain MH, Alizai N, Patel B. Outcomes of laparoscopic Kasai portoenterostomy for biliary atresia: A systematic review. J Pediatr Surg 2017; 52: 264-7.

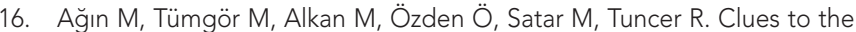
diagnosis of biliary atresia in neonatal cholestasis. Turk J Gastroenterol 2016; 27: 37-41.

17. Morris AL, Bukauskas K, Sada RE, Shneider BL. Byler disease: early natural history. J Pediatr Gastroenterol Nutr 2015; 60: 460-6.

18. Tiker F, Tarcan A, Kilicdag H, Gurakan B. Early onset conjugated hyperbilirubinemia in newborn infants. Indian J Pediatr 2006; 73: 409-12.

19. McDiarmid SV, Anand R, Lindblad AS. Studies of Pediatric Liver Transplantation: 2002 update. An overview of demographics, indications, timing, and immunosuppressive practices in pediatric liver transplantation in the United States and Canada. Pediatr Transplant 2004; 8: 284-94.

20. Haberal M, Sevmis S, Karakayali H, Ozcay F, Moray G, YIlmaz U, et al. Pediatric liver transplant: results of a single center. Exp Clin Transplant 2008; 6: 7-13.

21. Zeytunlu M, Uğuz A, Ünalp Ö, Ergün $O$, Karasu Z, Günşar F, et al. Results of 1001 liver transplantations in 23 years: Ege University experience. Turk J Gastroenterol 2018; 29: 664-8. 